\title{
BMJ Open COVID-19 outcomes in UK centre within highest health and wealth band: a prospective cohort study
}

Gie Ken-Dror (iD , ${ }^{1}$ Charles Wade, ${ }^{2}$ Shyam Sharma, ${ }^{3}$ Jessica Law, ${ }^{4}$ Cristina Russo, ${ }^{4}$ Aarti Sharma, ${ }^{5}$ Elizabeth Joy, ${ }^{4}$ Joshua John, ${ }^{6}$ Jonathan Robin, ${ }^{4}$ Sarah John, ${ }^{7}$ Karim Mahana, ${ }^{4}$ David Fluck, ${ }^{4}$ Paul Bentley, ${ }^{8}$ Pankaj Sharma ${ }^{1,2}$

To cite: Ken-Dror G, Wade C, Sharma S, et al. COVID-19 outcomes in UK centre within highest health and wealth band: a prospective cohort study. BMJ Open 2020;10:e042090. doi:10.1136/ bmjopen-2020-042090

- Prepublication history for this paper is available online. To view these files, please visit the journal online (http://dx.doi. org/10.1136/bmjopen-2020042090).

Received 27 June 2020 Revised 02 September 2020 Accepted 05 October 2020
Check for updates

(C) Author(s) (or their employer(s)) 2020. Re-use permitted under CC BY-NC. No commercial re-use. See rights and permissions. Published by BMJ.

For numbered affiliations see end of article.

Correspondence to Professor Pankaj Sharma; pankaj.sharma@rhul.ac.uk

\section{ABSTRACT}

Objectives To describe the characteristics and outcomes of hospitalised patients with COVID-19 from UK in the highest decile of health and gross regional products per capita.

Design Prospective cohort study.

Setting Recruited all adult inpatients with laboratoryconfirmed COVID-19 symptoms admitted to a single Surrey centre between March and April 2020. Extensive demographic details were documented.

Outcome measure COVID-19 status of alive/dead and intensive care unit (ICU) status of yes/no.

Participants Patients with COVID-19 from Surrey centre UK $(\mathrm{n}=429)$.

Results 429 adult inpatients (mean age $70 \pm 18$ years; men $56.4 \%$ ) were included in this study, of whom, $19.1 \%$ required admission to ICU and $31.9 \%$ died. Adverse outcomes were associated with age (OR with each decade of years: $1.78,95 \% \mathrm{Cl} 1.53$ to $2.11, \mathrm{p}<0.001$ for mortality); male gender $(0 \mathrm{R}=1.08,95 \% \mathrm{Cl} 0.72$ to $1.63, \mathrm{p}=0.72$, present in $70.7 \%$, of admissions to ICU versus $53 \%$ of other cases, $p=0.004)$; cardiac disease $(0 R=3.43,95 \% \mathrm{Cl}$ 2.10 to $5.63, p<0.001)$, diabetes mellitus $(\mathrm{OR}=2.37$, $95 \% \mathrm{Cl} 1.09$ to $5.17, \mathrm{p}=0.028)$ and dementia $(\mathrm{OR}=5.06$, $95 \% \mathrm{Cl} 2.79$ to $9.44, \mathrm{p}<0.001)$. There was no significant impact of ethnicity or body mass index on disease outcome.

Conclusions Despite reports of worse outcomes in deprived regions, we show similar complication and mortality rates due to COVID-19 in an affluent and high life expectancy region.

\section{INTRODUCTION}

An emerging theme of SARS-CoV-2 infection is wide variability in incidence, presentation and prognosis, between countries ${ }^{1}$ and between regions within countries. $^{2} 3$ Understanding which factors underpin this heterogeneity is critical to understanding the biology of COVID-19 and guiding therapeutic and preventative strategies.

One of the most surprising findings for an infectious disease is that nations with high gross domestic product per capita show higher rates of COVID-19 infection, and

\section{Strengths and limitations of this study}

- Sample size with established outcome is greater than many other UK COVID-19 cohorts.

- Surrey represents the greatest proportion of high socioeconomic status residents compared with anywhere else in the UK.

The number of patients from any one ethnic group was limited.

mortality, than nations with lower economic performance. ${ }^{1}$ Possible explanations for this paradox include richer nations tending to have larger cities, whose inhabitants travel more widely, are older, and have higher rates of cardiovascular disease, diabetes and obesity-all recognised adverse prognostic features. ${ }^{45}$ Recent data from the UK and USA suggest that contrary to this international trend, regional deprivation is strongly associated with higher COVID-19-associated mortality, ${ }^{6-8}$ which may reflect differences in ethnic profile, background health, social ${ }^{9}$ and behavioural factors of transmission ${ }^{10}$ and public health infrastucture. $^{7}$

When comparing regions, differences in personal factors like demographic or health status can be complicated by local organisational differences like hospital capacity or primary care referral patterns. To help tease apart these factors, we present a large cohort of COVID-19 infections admitted to a single UK centre covering one geographical region, Surrey county, ${ }^{11-13}$ which represents one of the most affluent and homogeneous populations in the UK. The gross regional domestic product per capita of Surrey and healthy life expectancy are both within the top UK deciles while levels of adult obesity, smoking and physical inactivity are significantly lower than the national average,${ }^{14}$ with $90.4 \%$ being white ${ }^{14}$ higher than the national average. ${ }^{11}$ 
From this relatively healthy and socially advantaged cohort, we questioned whether demographic, clinical outcome and prognostic features of COVID-19 infection differ from those described in more diverse and deprived international regions.

\section{METHODS}

This study includes adult inpatients ( $\geq 18$ years old) from St Peters Hospital, Surrey. We included all prospective patients with laboratory-confirmed COVID-19 infection who were admitted between March and April 2020. The recruitment dates incorporate the initial surge of cases seen in the UK, the estimated peak and the subsequent decline. Case confirmation was defined by a positive result on a COVID-19 reverse-transcription-polymerase chain reaction assay of a specimen collected on a nasopharyngeal swab. Demographic data were manually extracted from electronic health records.

Extensive patient data were collected and analysed from admission through to completion of the episode of care and included demographics, exposure history, typical symptomatology, comorbidities, treatment, complications and outcome. Many participants were coenrolled in other interventional studies and clinical trials.

\section{Data analysis}

Descriptive statistics were summarised using mean with SD or median with IQR for continuous variables and proportion for categorical variables. The $\chi^{2}$ was used for single factor analysis of categorical variables. Independent t-test or Mann-Whitney U test was used for single factor analysis of continuous variables. Univariate and multivariate logistic regressions were used to estimate the associations of risk factors with COVID-19 status. The subset of risk factor providing the best fit to the data, among all the possible models, was selected using stepwise model selection by number of criteria: Akaike information criterion (AIC), Bayesian information criterion, Mallow's Cp, residual mean square, a leave-one-out cross-validation, receiver operating characteristic curve (ROC curve), Youden index and conditional analysis. To check how sample size affects the results of variable selection procedure, we randomly selected a proportion of the original dataset to apply the stepwise AIC procedure used in the main analysis and repeated the procedure 1000 times. The significance threshold is a trade-off between avoidance of false-positive associations while considering the likely higher prior of association because of the nature of the array. However, there are high correlations between pairs variables, therefore, the Bonferroni correction would be too conservative for the analysis. In addition, type-I errors are random, and patterns in results that confirm previous reports should be given more weight than isolated results with a single low $p$ value. Correction for multiple comparisons largely increases the likelihood of type-II errors and important differences considered non-significant. To consider this, for individual tests of association, rather than applying a correction for multiple testing at global significance level, defined statistical significance as 0.01 . Analyses and graphics were performed and produced using R V.4.0.0.

\section{Patient and public involvement}

This study was undertaken during the height of the UK coronavirus pandemic. It was not possible for patients or their advisors to be involved in the design of this study.

\section{RESULTS}

A total of 429 patients were included, none of whom were lost to follow-up. Patients were typically elderly (mean age: $70 \pm 18$ years), men $(56.4 \%)$ and white $(72.5 \%)$. Comorbidity and symptom frequencies are shown in table 1. Only small fractions of patients had recently travelled to a country with known transmission $(1.2 \%)$ or had recent contact with a person known to have confirmed COVID-19 (5.4\%).

\section{Course and outcome}

The proportion of patients requiring admission to intensive care unit (ICU) was $82 / 429$ (19.1\%), $14.2 \%$ of which required non-invasive ventilation and $7 \%$ required invasive ventilation. Patients who were admitted were significantly younger (mean age of ICU admission $65 \pm 17$ years vs $71 \pm 18$ years $(\mathrm{p}=0.002)$ and overwhelmingly men $(70.7 \%$, vs $53 \%$ of non-ICU patients, $\delta=17.7 \%, 95 \%$ CI $7 \%$ to $29 \%$; $\mathrm{p}=0.004)($ table 1$)$.

Superadded bacterial pneumonia was diagnosed in 28 patients $(6.5 \%)$. The most common complications of infection included viral pneumonia (23.3\%), acute respiratory syndrome $(13.1 \%)$, acute kidney injury $(7.9 \%)$, all of which were associated with death ( $\mathrm{p}$ values all $<0.001$ ). Nine $(2.1 \%)$ patients required renal replacement therapy or dialysis.

\section{Prognostic factors}

The strongest risk factor for mortality in COVID-19 was age (OR=1.78 for each decade of life, $95 \%$ CI 1.53 to 2.11, $\mathrm{p}<0.001$ ) (figure 1). Symptoms associated with mortality were dehydration, altered consciousness or confusion and increased respiratory rate ( $p$ values all $<0.001)$. Conversely, myalgia $(\mathrm{p}=0.006)$, sore throat $(\mathrm{p}=0.011)$, fever $(\mathrm{p}=0.021)$ and cough $(\mathrm{p}=0.048)$ at presentation were associated with reduced mortality (table 1 ). Interesting, absence of fever and cough was associated with increased risk of death $(\mathrm{p}=0.007)$. On arrival to hospital, those who died had a significant difference in respiratory rate (survivor mean respiratory rate $22 \pm 8$ vs $26 \pm 9$ in nonsurvivors; $\mathrm{p}=0.001$ ).

The mortality OR for continuous (figure 2) and binary (figure 3) variables are shown. Gender, body mass index (BMI) and smoking status were not significantly related to worse outcomes (table 1). Patients from non-European descent were nearly three times more likely to be admitted to hospital, but their overall outcome has no different 


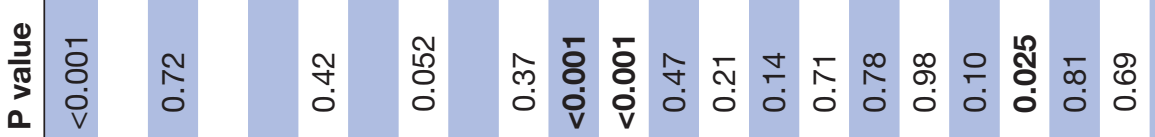

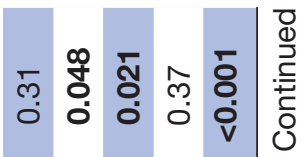

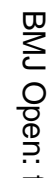

a

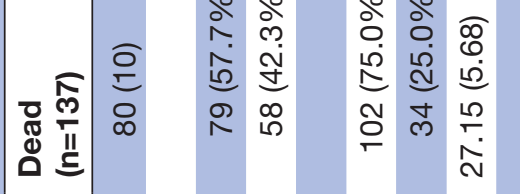

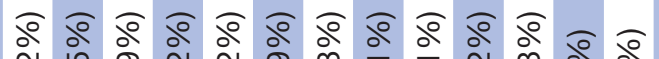

व. กั

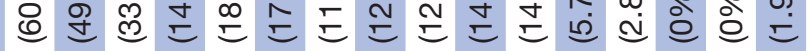

ले ले ले फ़

占造 สำ

œ 8 i

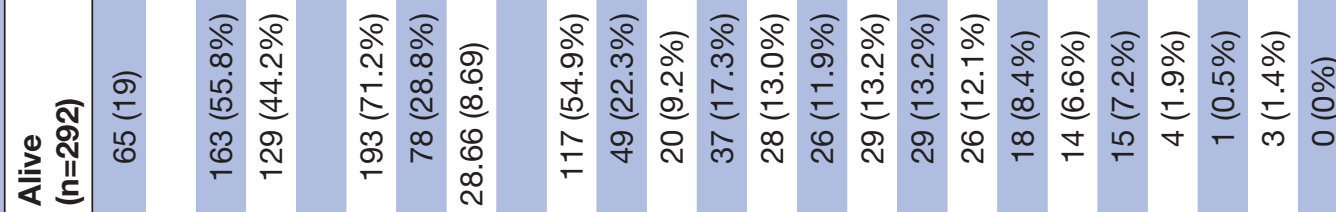

9.

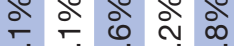
ก

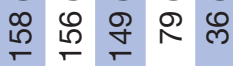

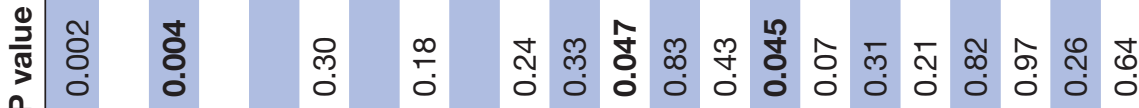

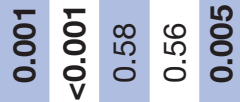

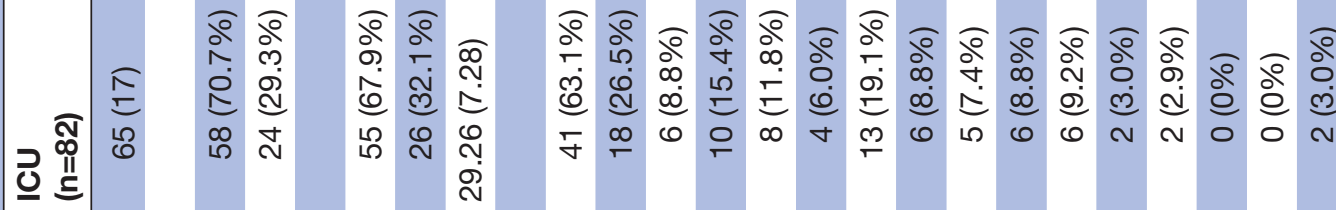

응

वे ठे ले में

$\underset{\infty}{\infty}$ 它

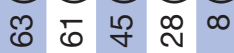

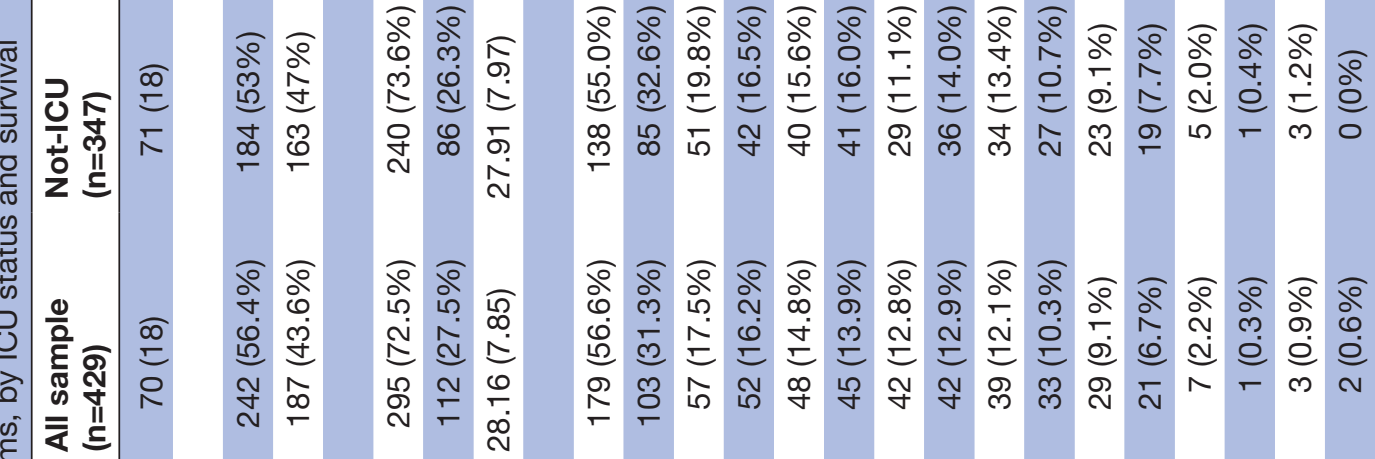

$\widehat{0} \widehat{0} \widehat{0}$

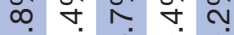
बै

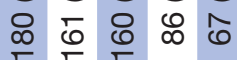
至

$\stackrel{N}{\sim} \underset{\sim}{\stackrel{\infty}{\sim}}$

$\widehat{0} \widehat{0} \overline{0}$

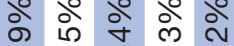

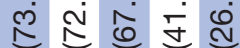

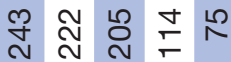

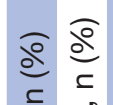

$\frac{1}{c}$

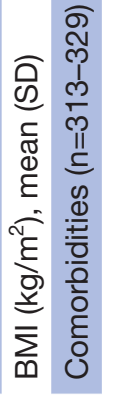

నิ ฺำ

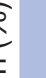

을

จิ

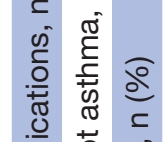

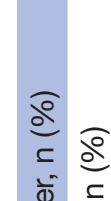

$\sqrt{\mathrm{c}}$

कัष

$\frac{\sqrt{0}}{\frac{0}{0}}$

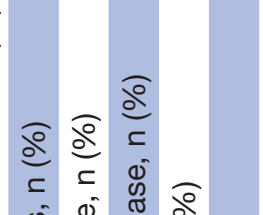

$\frac{\sqrt{9}}{5}$

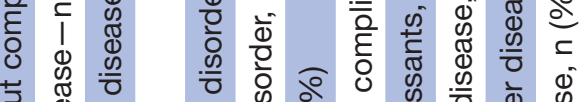

ลิ

ङ

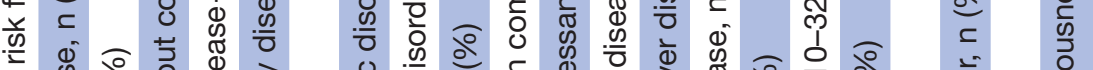

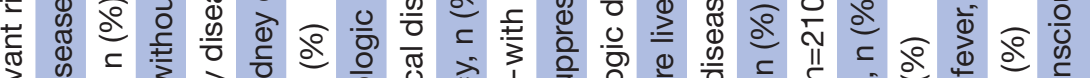

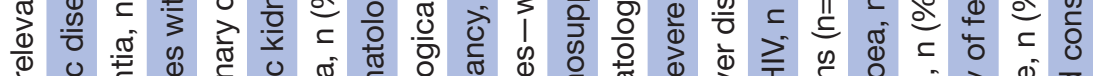

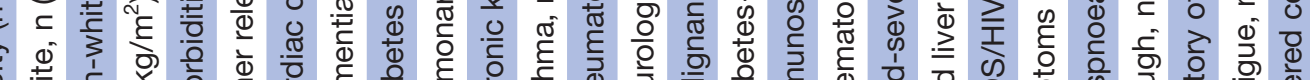

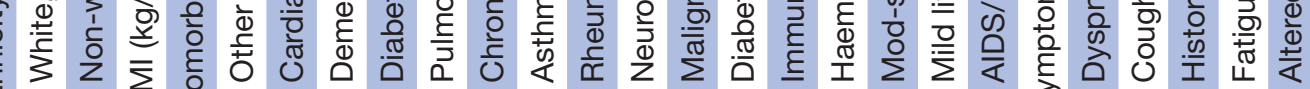
के 


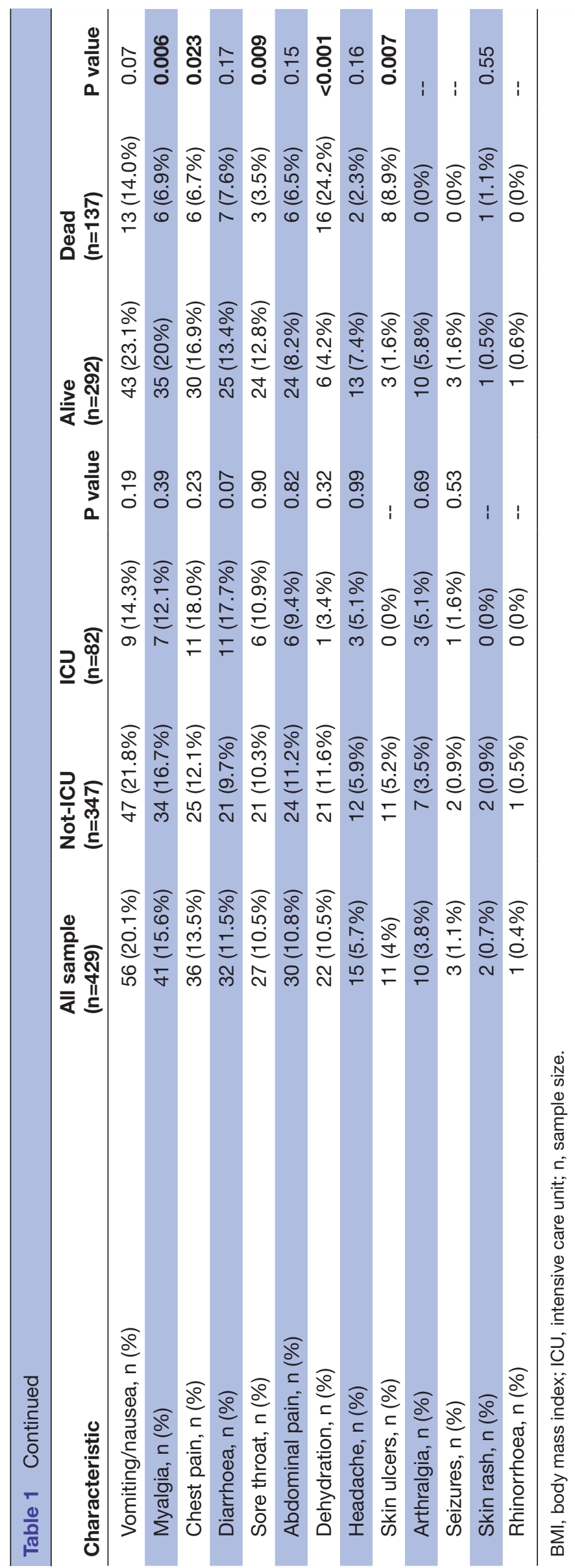

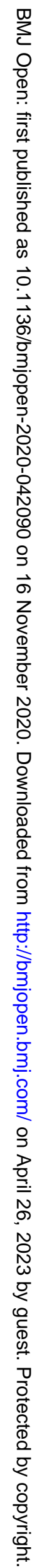




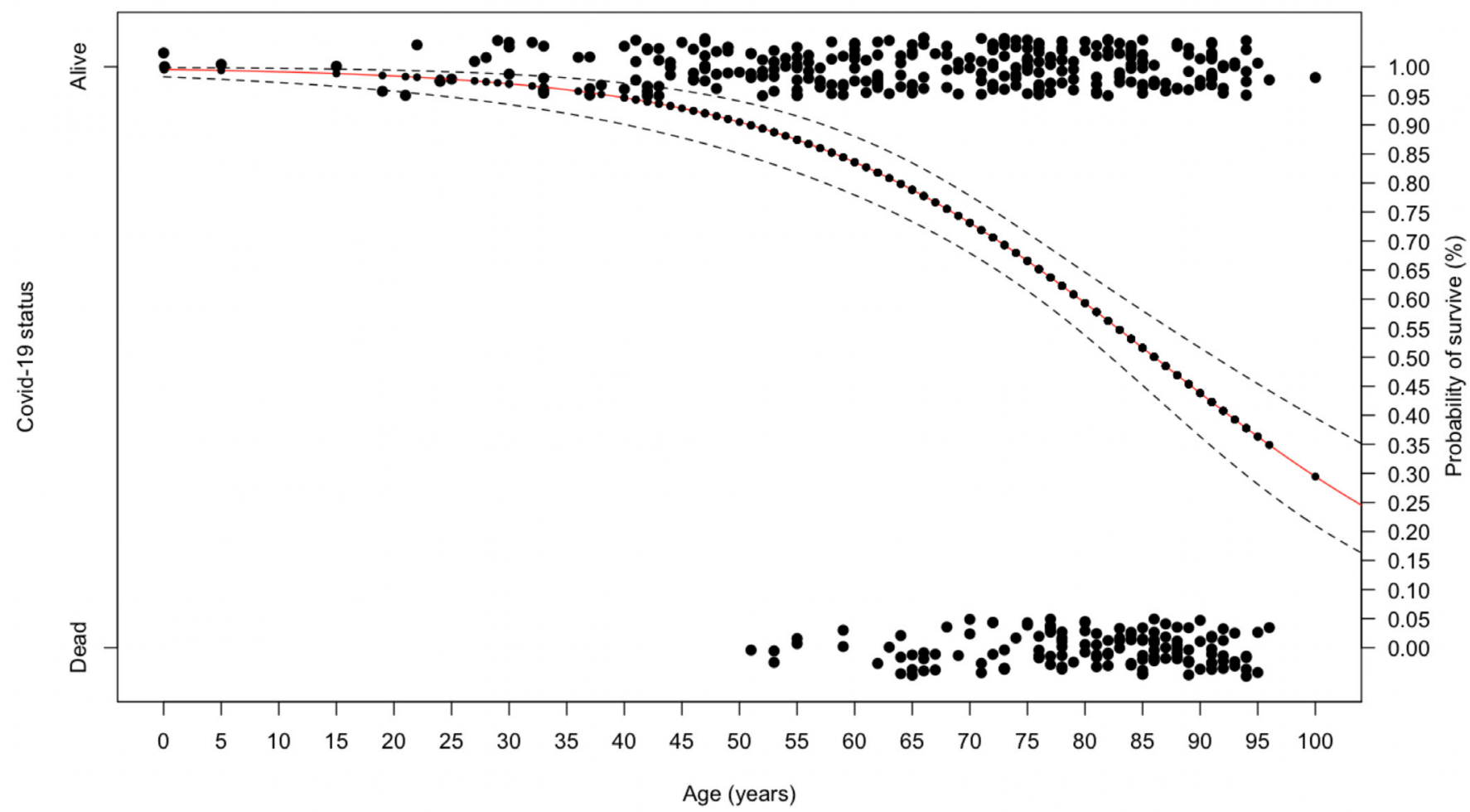

Figure 1 Probability of survival from COVID-19\% and 95\% Cls among age.

compared with Caucasian patients, although representation by different ethnicity groups was low in this region.

The predictive probability of death from COVID-19 was analysed using the ROC curve (area under the curve $=0.86, \mathrm{p}<0.0001$ ). We modelled six factors (age, $\mathrm{C}$ reactive protein (CRP), respiratory rate, diastolic blood pressure (BP), presence of dementia, asthma), which together explain $86 \%$ variance of mortality (table 2 ).

\section{DISCUSSION}

We describe a large cohort of confirmed patients with COVID-19 treated in a single hospital from one of the most affluent, socially homogeneous and healthy regions of the UK. ${ }^{11-13}$ Despite this regional advantage, the mortality (32\%) and admission to ICU (19\%) rates in hospitalised COVID-19 cases are similar to provisional reports elsewhere in the country. ${ }^{15-17}$ Our finding that adverse outcomes for hospitalised patients from a wealthy, healthy region occurred at a similar frequency as recorded elsewhere in the UK lies in contrast to population-level data showing that mortality worsens with regional social deprivation and underlying health status. ${ }^{6-8}$ Among UK regions, age-standardised mortality rates due to COVID-19 were $118 \%$ higher in the highest deciles deprived regions, compared with the lowest deciles deprived area. ${ }^{8}$ Individual deprivation was also found to be an independent predictor of hospital mortality in an electronic health analysis of 17 million English healthcare records featuring 5683 COVID-19 deaths.

One possible explanation for similar rates of adverse outcomes as cohorts elsewhere in UK is that hospitalised patients had a high level of recognised risk factors, even if these features were less common as a whole relative to the national average. This is seen in the demographic structure of admitted cases, with the average age being 70 years old, and men accounting for $56 \%$ these profiles previously associated with adverse outcomes ${ }^{7} 18$ and comparable in proportion to those recorded from a UK-wide survey of COVID-19-hospitalised cases (median age: 72 years; $60 \%$ men).$^{19}$ Additionally, the proportion of non-whites, a further risk for mortality, ${ }^{16}$ accounted for a disproportionately greater fraction of admissions $(27.5 \%)$, than in Surrey as a whole $(10 \%)$; while the rate of relevant comorbidities (eg, cardiovascular disease) was as high in our cohort as in other UK cohorts, although the numbers represented by each ethnic group is relatively low. ${ }^{17}$ Thus, the high-risk profile of hospitalised Surrey cohort patients helps to explain why their rate of adverse outcomes is similar to those reported in more deprived areas. Our results also suggest that inter-regional differences in COVID-19 outcome (eg, higher death rate in deprived areas $)^{8}$ are more likely to be due to differences in frequencies of personal risk factors, rather than due 


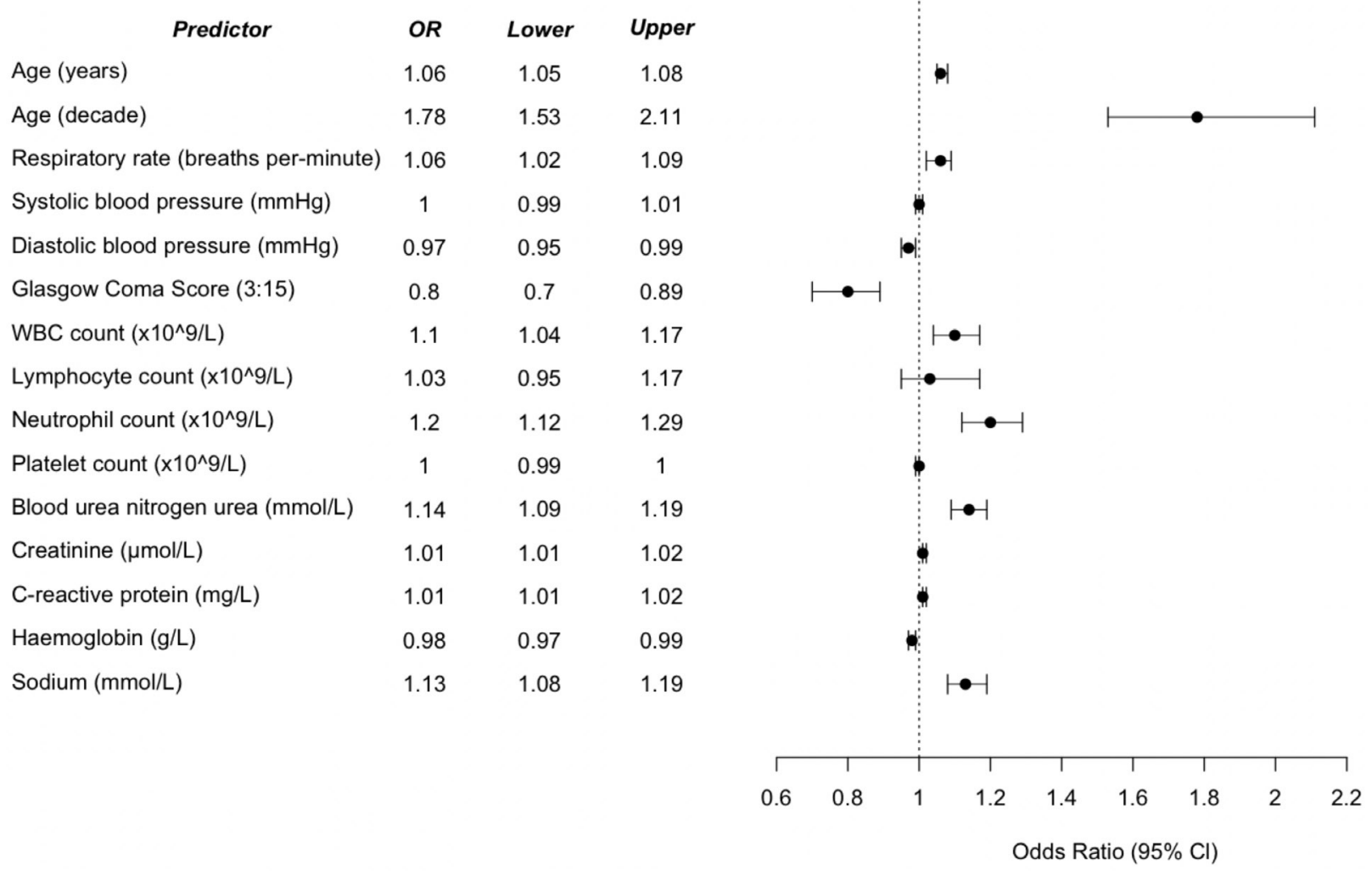

Figure 2 Forest plot showing the OR of death as outcome using logistic regression analysis for risk factor as continuous variables.

to variations in local healthcare structure, capability or intensive care capacity.

Data from the Intensive Care National Audit and Research Centre showed that a third of patients with COVID-19 admitted to critical care units are from an ethnic minority background. ${ }^{20}{ }^{21}$ Of 2249 patients admitted to 201 critical care units in England, $64.8 \%$ were white, $13.8 \%$ were Asian, $13.6 \%$ were black and $7.8 \%$ were from other or mixed ethnic groups. Importantly, these unadjusted descriptive data take no account of factors other than ethnicity that could influence the risk of critical care admission. Ethnic minority groups have also been disproportionately affected by COVID-19 in the USA, highlighting potential racial, economic and other inequalities. ${ }^{20}$ An analysis by the Washington Post reports that those counties with black majorities have three times the rate of COVID-19 cases and almost six times the rate of deaths, compared with counties where white residents are in the majority. ${ }^{20}$ However, unlike the UK, the US experience may be influenced by the lack of universal healthcare and caution is required when extrapolating across different health systems. The higher observed incidence and severity in minority groups may be associated with socioeconomic, cultural or lifestyle factors, genetic predisposition or pathophysiological differences in susceptibility or response to infection. Possible susceptibilities include an increased risk of admission for acute respiratory tract infections, ${ }^{22}$ an increased prevalence of Vitamin D deficiency, ${ }^{23}$ vaccination policies in their country of birth and immune effects, ${ }^{20}$ increased inflammatory burden and higher prevalence of cardiovascular risk factors such as insulin resistance and obesity than white populations. ${ }^{24}$ Some of these are also risk factors for increased disease severity in COVID-19. ${ }^{2025}$

In other respects, the characteristics and prognostic factors of our COVID-19 cohort were broadly similar to those described in cohorts from more diverse regions, with lower economic and health status. ${ }^{17} \mathrm{~A}$ third of admissions were apyrexial; one-third had no cough and $15 \%$ had neither a cough or fever, indicating that a sizeable fraction of hospitalised cases do not meet current NHS England clinical criteria for suspected COVID-19 infection. ${ }^{26}$ Indeed, the absence of a cough and fever was associated with a poorer outcome. Fever is the most common symptom among mild to moderate cases. ${ }^{27-37}$ However, the frequency varied among the studies. In the largest cohort study in Europe, fever was presented in $45.4 \%$ of the cases ${ }^{33}$ while in the two largest studies in China, it was present at more than $80 \%{ }^{35} 36$. Cough was the second most common symptom observed in all studies. ${ }^{27-37}$ The frequency with which it was observed varied among studies, and it was up to $63.2 \%$ in the largest European study $^{33}$ and between $48.7 \%{ }^{36}$ and $65.5 \%^{35}$ in the two largest Chinese studies. Cough was observed in $65.7(95 \%$ CI 57.8 to 73.5) of patients with non-severe disease in the systematic review of studies in the general population ${ }^{38}$ 


\begin{tabular}{|c|c|c|c|}
\hline Predictor & OR & Lower & Uppe \\
\hline Self reported feverishness $38 \mathrm{C}$ & 0.5 & 0.31 & 0.8 \\
\hline Cough self report & 0.6 & 0.37 & 0.98 \\
\hline Oxygen saturation & 0.38 & 0.22 & 0.65 \\
\hline History of fever & 0.55 & 0.33 & 0.92 \\
\hline Cough & 0.59 & 0.35 & 1 \\
\hline Sore throat & 0.23 & 0.05 & 0.67 \\
\hline Chest pain & 0.36 & 0.13 & 0.84 \\
\hline Muscle aches Myalgia & 0.3 & 0.11 & 0.69 \\
\hline Altered consciousness confusion & 3.07 & 1.78 & 5.34 \\
\hline Chronic cardiac disease/congenital heart diseas & 3.43 & 2.1 & 5.63 \\
\hline Obesity as defined by clinical staff & 0.3 & 0.12 & 0.66 \\
\hline Diabetes with complications & 2.37 & 1.09 & 5.17 \\
\hline Dementia & 5.06 & 2.79 & 9.44 \\
\hline Malnutrition & 2.44 & 1.03 & 5.82 \\
\hline Current admission to ICU/IMC/HDU & 2.63 & 1.5 & 4.66 \\
\hline Non invasive ventilation BIPAP/CPAP & 3.14 & 1.72 & 5.8 \\
\hline Invasive ventilation & 2.46 & 1.15 & 5.32 \\
\hline High flow nasal canula oxygen therapy & 1.92 & 1.17 & 3.14 \\
\hline Clinical pneumonia & 2.83 & 1.48 & 5.65 \\
\hline ICU or High Dependency admission & 3.9 & 1.86 & 8.47 \\
\hline Invasive ventilation & 2.95 & 1.28 & 6.94 \\
\hline Inotropes vasopressors & 3.97 & 1.6 & 10.4 \\
\hline Viral Pneumonia & 2.58 & 1.5 & 4.4 \\
\hline Bacterial pneumonia & 2.45 & 1.1 & 5.48 \\
\hline Anaemia & 2.22 & 1.15 & 4.2 \\
\hline
\end{tabular}

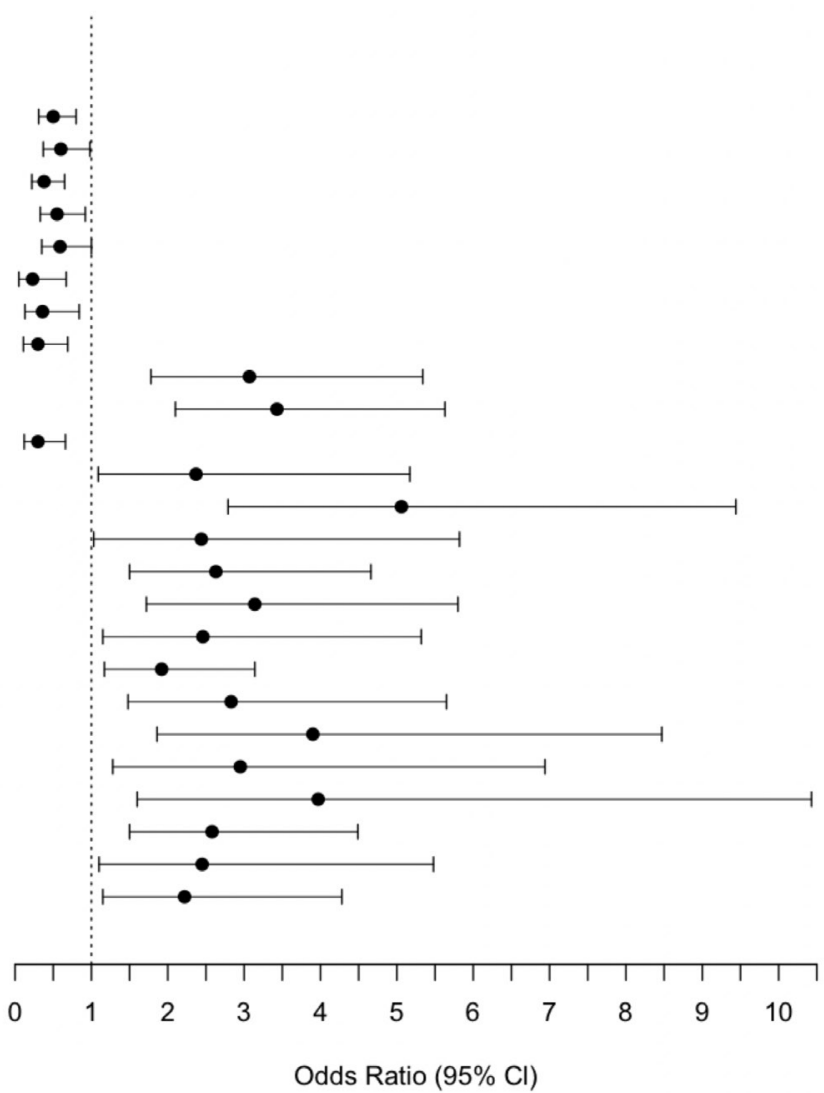

Figure 3 Forest plot showing the OR of death as outcome using logistic regression analysis for risk factor as binary variables. BIPAP, Bi-level Positive Airway Pressure; CPAP, Constant Positive Airway Pressure; HDU, High Dependency Unit; ICU, intensive care unit; IMC, Intermediate Care unit.

and $46 \%$ of the systematic review of paediatric studies. ${ }^{31}$ The biological mechanism of absence of fever or cough is unclear. It is possible that failure to mount an immune response is the reason for the poor outcome in the absence of fever or cough.

The strongest factor predicting COVID-19-associated mortality in our cohort was age, risk increasing by $6 \%$ with every additional year of life or by $78 \%$ with every additional decade (figure 2). This is similar to a study from China (OR per year increase $1.10, \mathrm{p}=0.0043)^{39}$ and an international analysis (60 years old or older patients have an $\mathrm{OR}=18.8$ $(95 \% \text { CI } 7.20 \text { to } 41.6)^{40}$ as well as clinical characteristics from coronaviruses causing SARS and Middle East Respiratory Syndrome epidemics. ${ }^{39}$ Strong associations of mortality were also seen with dementia, asthma, diastolic BP inline with other published literature ${ }^{4142}$ as well as respiratory rate and CRP levels.

Table 2 Multivariate logistic regression analysis of COVID-19 risk factors

\begin{tabular}{|c|c|c|c|}
\hline Risk factor & $\begin{array}{l}\text { Model } 1 \\
\text { OR }(95 \% \mathrm{Cl}) \mathrm{P} \text { value }\end{array}$ & $\begin{array}{l}\text { Model } 2 \\
\text { OR }(95 \% \mathrm{Cl}) \mathrm{P} \text { value }\end{array}$ & $\begin{array}{l}\text { Model } 3 \\
\text { OR }(95 \% \mathrm{Cl}) \mathrm{P} \text { value }\end{array}$ \\
\hline Age (decade) & $1.78(1.53$ to 2.11$)<0.001$ & $1.89(1.46$ to 2.52$)<0.001$ & $1.89(1.46$ to 2.52$)<0.001$ \\
\hline Respiratory rate (breaths per minute) & & 1.05 (1.01 to 1.10$) 0.019$ & 1.05 (1.01 to 1.10$) 0.013$ \\
\hline DBP $(5 \mathrm{mmHg})$ & & 0.87 (0.79 to 0.97$) 0.012$ & $0.87(0.77$ to 0.97$) 0.015$ \\
\hline Asthma & & & 3.22 (1.16 to 8.92$) 0.023$ \\
\hline $\mathrm{AIC}$ & 473.83 & 248.84 & 224.65 \\
\hline Sensitivity/specificity & $0.84 / 0.51$ & $0.86 / 0.67$ & $0.70 / 0.86$ \\
\hline AUC $(95 \% \mathrm{Cl})$ & $0.72(0.68$ to 0.77$)$ & $0.83(0.78$ to 0.88$)$ & $0.86(0.81$ to 0.91$)$ \\
\hline
\end{tabular}

AIC, Akaike information criterion; AUC, area under the curve; CRP, C reactive protein; ; DBP, diastolic blood pressure. 
The admission rate to intensive care in our COVID-19 cohort $(19 \%)$ was similar to reports from Italy $(10 \%)$ and America $(14 \%),{ }^{41} 43$ but significantly lower than China $(26 \%) .{ }^{39}$ Cough at presentation, lymphocytopenia and raised alanine aminotransferase (ALT) discriminated between those who could and those who could not avoid ICU admission, in line with other published data. ${ }^{35}$ However, factors we found that predicted fatality in ICU were raised urea and raised creatinine, which have not yet been reported elsewhere. Of those admitted to ICU, $47.6 \%$ died, compared with $28.4 \%$ who received ward-based care. This is line with national data $(45 \%)^{19}$ and compares to a broad international range early Chinese data $16 \%-78 \%$, Italy 26\%, USA 50\%. ${ }^{194-46}$

Our modelling data predict six factors that account for $86 \%$ of the mortality variance with age being the best predictor, accounting for $72 \%$ of the model by itself (table 2). One prognostic association in our cohort that differs from other reports ${ }^{46-48}$ is that BMI was not a statistically significant factor predicting mortality, despite the average BMI of admitted patients being raised $\left(28 \mathrm{~kg} / \mathrm{m}^{2}\right)$. In fact, we found that raised BMI shows a trend towards protection in women. An obesity survival paradox with pneumonia has previously been described ${ }^{49}$ and may arise because of more aggressive treatment provided to these patients or increased metabolic reserve enabling prolonged treatment in intensive care. The fact that 'protective obesity' was found only in women suggests there may also be some role of or difference in sex hormones and fat deposition patterns. Another reason for discrepancies between reports in the effect of BMI on survival may arise from the method by which BMI was measured. Using a different measure of obesity ('recognised by clinical staff') led to a significantly positive association with mortality, as observed elsewhere. ${ }^{19}$

There are several limitations to our study. First, as we are still early in our epidemic, $10.5 \%$ patients do not yet have final outcomes established, but our sample size of those who do have an established outcome is still greater than many other UK COVID-19 cohorts. While we recognise that the cohort was drawn from a region with high socioeconomic status, it is difficult to know the extent of this status in individual patients. However, Surrey represents the greatest proportion of high socioeconomic status residents compared with anywhere else in the UK. Although we show a high rate of admission to hospital for patients from different ethnic backgrounds there is no overall outcome difference, this result must be interpreted with caution as the number of patients from any ethnic group was limited.

\section{CONCLUSIONS}

We show that rates of complication and death due to COVID-19 are as high in a UK region in the top deciles of health and financial well-being as other populations described elsewhere. The findings underscore the potential universal reach of the disease regardless of socioeconomic background.

\section{Author affiliations}

${ }^{1}$ Institute of Cardiovascular Research, Royal Holloway University of London, Egham, UK

${ }^{2}$ Department of Clinical Neuroscience, Imperial College Healthcare NHS Trust, London, UK

${ }^{3}$ College of Medicine, University of Edinburgh, Edinburgh, Scotland

${ }^{4}$ Division of Medicine, Ashford and Saint Peter's Hospitals NHS Foundation Trust, Chertsey, UK

${ }^{5}$ School of Medicine, Imperial College London, London, UK

${ }^{6}$ School of Medicine, Kings College London, London, UK

${ }^{7}$ Murray Edwards College, University of Cambridge, Cambridge, UK

${ }^{8}$ Department of Brain Sciences, Imperial College London, London, UK

\section{Twitter Jessica Law @jessicaalaw24}

Acknowledgements We thank all the patients, relatives and NHS staff involved in this study, without whom this work would not have been possible. Some data used for analysis was derived from our own data submitted to CCP-UK, to whom we are grateful.

Contributors PS conceived and designed the study. GK-D, and PS performed the data analysis and interpreted the results. GK-D conducted statistical analysis. CW wrote the first draft. SS, JL, CR, AS, EJ, JJ, JR, SJ, KM, DF, PB helped collect data for the hospital. PS and GK-D edited subsequent versions of the manuscript. All authors contributed to the final version of the manuscript. PS accepts overall responsibility for this manuscript.

Funding The authors have not declared a specific grant for this research from any funding agency in the public, commercial or not-for-profit sectors.

Competing interests None declared.

Patient and public involvement Patients and/or the public were not involved in the design, or conduct, or reporting, or dissemination plans of this research.

\section{Patient consent for publication Not required.}

Ethics approval All patients were from the UK and ethical approval was obtained from Ashford and St Peters Hospital Ethics Committee. Ashford \& St Peters Hospital, Surrey Human Ethics Committee, reference number: 2020PS01.

Provenance and peer review Not commissioned; externally peer reviewed. Data availability statement № data are available.

Open access This is an open access article distributed in accordance with the Creative Commons Attribution Non Commercial (CC BY-NC 4.0) license, which permits others to distribute, remix, adapt, build upon this work non-commercially, and license their derivative works on different terms, provided the original work is properly cited, appropriate credit is given, any changes made indicated, and the use is non-commercial. See: http://creativecommons.org/licenses/by-nc/4.0/.

ORCID iD

Gie Ken-Dror http://orcid.org/0000-0003-3747-7112

\section{REFERENCES}

1 Dowd JB, Andriano L, Brazel DM, et al. Demographic science AIDS in understanding the spread and fatality rates of COVID-19. Proc Natl Acad Sci U S A 2020;117:9696-8.

2 Wadhera RK, Wadhera P, Gaba P, et al. Variation in COVID-19 hospitalizations and deaths across New York City boroughs. JAMA 2020;323:2192.

3 Stier A, Berman M, Bettencourt L. COVID-19 attack rate increases with City size (March 30, 2020). Mansueto Institute for urban innovation research paper forthcoming. SSRN- Lancet prepublication 2020.

4 Wu Z, McGoogan JM. Characteristics of and important lessons from the coronavirus disease 2019 (COVID-19) outbreak in China. JAMA 2020;323:1239.

5 Zheng Z, Peng F, Xu B, et al. Risk factors of critical \& mortal COVID-19 cases: A systematic literature review and meta-analysis. $J$ Infect 2020;81:e16-25.

6 Dorn Avan, Cooney RE, Sabin ML. COVID-19 exacerbating inequalities in the US. Lancet 2020;395:1243-4.

7 Rose TC, Mason K, Pennington A, et al. Inequalities in COVID19 mortality related to ethnicity and socioeconomic deprivation. medRxiv 2020. 
8 Statistics TofN. Deaths involving COVID-19 by local area and socioeconomic deprivation: deaths occurring between 1 March and 17 April 2020.

9 Ramírez IJ, Lee J. COVID-19 emergence and social and health determinants in Colorado: a rapid spatial analysis. Int $J$ Environ Res Public Health 2020;17. doi:10.3390/ijerph17113856. [Epub ahead of print: 29 May 2020].

10 Holtgrave DR, Barranco MA, Tesoriero JM, et al. Assessing racial and ethnic disparities using a COVID-19 outcomes continuum for new York state. Ann Epidemiol 2020;48:9-14.

11 Surrey Heath. census, 2011. Available: https://www.surreyheath. gov.uk/business/economic-development/census-and-demographicinformation/census-2011

12 England PH. Long term conditions. Available: https://www. newscientist.com/article/2238847-uk-science-advisers-expectcoronavirus-epidemic-to-peak-within-a-month

13 Surrey Public Health. Joint strategic needs assessment: economy, employment, deprivation.

14 NHS Digital. Health Survey for England 2017 [NS]. Available: https:// digital.nhs.uk/data-and-information/publications/statistical/healthsurvey-for-england/2017

15 GOV.UK. Coronavirus (COVID-19) in the UK 2020.

16 Statistics NE. COVID-19 daily deaths.

17 Tomlins J, Hamilton F, Gunning S, et al. Clinical features of 95 sequential hospitalised patients with novel coronavirus 2019 disease (COVID-19), the first UK cohort. J Infect 2020;81:e59-61.

18 Pareek M, Bangash MN, Pareek N, et al. Ethnicity and COVID-19: an urgent public health research priority. Lancet 2020;395:1421-2.

19 Docherty AB, Harrison EM, Green CA, et al. Features of 16,749 hospitalised UK patients with COVID-19 using the ISARIC who clinical characterisation protocol. medRxiv 2020.

20 Khunti K, Singh AK, Pareek M, et al. Is ethnicity linked to incidence or outcomes of covid-19? BMJ 2020;369:m1548.

21 Centre ICNAaR. Covid-19 study case mix programme 2020

22 Simpson CR, Steiner MF, Cezard G, et al. Ethnic variations in morbidity and mortality from lower respiratory tract infections: a retrospective cohort study. J R Soc Med 2015;108:406-17.

23 Martineau AR, Jolliffe DA, Hooper RL, et al. Vitamin D supplementation to prevent acute respiratory tract infections: systematic review and meta-analysis of individual participant data. BMJ 2017;356:i6583.

24 Tillin T, Forouhi NG, McKeigue PM, et al. Southall and Brent revisited: cohort profile of sabre, a UK population-based comparison of cardiovascular disease and diabetes in people of European, Indian Asian and African Caribbean origins. Int J Epidemiol 2012;41:33-42.

25 Garg S, Kim L, Whitaker M, et al. Hospitalization Rates and Characteristics of Patients Hospitalized with Laboratory-Confirmed Coronavirus Disease 2019 - COVID-NET, 14 States, March 1-30, 2020. MMWR Morb Mortal Wkly Rep 2020;69:458-64.

26 GOV.UK. COVID-19: investigation and initial clinical management of possible cases. GovUk 2020:1-5 https://www.gov.uk/government/ publications/wuhan-novel-coronavirus-initial-investigation-ofpossible-cases

27 Tian S, Hu N, Lou J, et al. Characteristics of COVID-19 infection in Beijing. J Infect 2020;80:401-6.

28 Yang W, Cao Q, Qin L, et al. Clinical characteristics and imaging manifestations of the 2019 novel coronavirus disease (COVID19):A multi-center study in Wenzhou city, Zhejiang, China. J Infect 2020;80:388-93.

29 Wu J, Liu J, Zhao X, et al. Clinical characteristics of imported cases of coronavirus disease 2019 (COVID-19) in Jiangsu Province: a multicenter descriptive study. Clin Infect Dis 2020;71:706-12.
30 Young BE, Ong SWX, Kalimuddin S, et al. Epidemiologic features and clinical course of patients infected with SARS-CoV-2 in Singapore. JAMA 2020;323:1488.

31 Chang T-H, Wu J-L, Chang L-Y. Clinical characteristics and diagnostic challenges of pediatric COVID-19: a systematic review and meta-analysis. J Formos Med Assoc 2020;119:982-9.

32 Zhao X-Y, Xu X-X, Yin H-S, et al. Clinical characteristics of patients with 2019 coronavirus disease in a non-Wuhan area of Hubei Province, China: a retrospective study. BMC Infect Dis 2020;20:311.

33 Lechien JR, Chiesa-Estomba CM, Place S, et al. Clinical and epidemiological characteristics of 1420 European patients with mild-to-moderate coronavirus disease 2019. J Intern Med 2020;288:335-44.

34 Kim G-u, Kim M-J, Ra SH, et al. Clinical characteristics of asymptomatic and symptomatic patients with mild COVID-19. Clin Microbiol Infect 2020;26:948.e1-948.e3.

35 Feng Y, Ling Y, Bai T, et al. COVID-19 with different severities: a multicenter study of clinical features. Am J Respir Crit Care Med 2020;201:1380-8.

36 Chen L, Deng C, Chen X, et al. Ocular manifestations and clinical characteristics of 535 cases of COVID-19 in Wuhan, China: a crosssectional study. Acta Ophthalmol 2020. doi:10.1111/aos.14472. [Epub ahead of print: 18 May 2020].

37 Michelen M, Jones N, Stavropoulou C. In patients of COVID-19, what are the symptoms and clinical features of mild and moderate cases? 2020. Available: https://www.cebm.net/covid-19/in-patients-ofcovid-19-what-are-the-symptoms-and-clinical-features-of-mild-andmoderate-case

38 Xianxian Zhao BZ, Li P, Ma C, et al. Incidence, clinical characteristics and prognostic factor of patients with COVID-19: a systematic review and meta-analysis. medRxiv 2020.

39 Zhou F, Yu T, Du R, et al. Clinical course and risk factors for mortality of adult inpatients with COVID-19 in Wuhan, China: a retrospective cohort study. Lancet 2020;395:1054-62.

40 Caramelo F, Ferreira N, Oliveiros B. Estimation of risk factors for COVID-19 mortality - preliminary results. medRxiv 2020.

41 Richardson S, Hirsch JS, Narasimhan M, et al. Presenting characteristics, comorbidities, and outcomes among 5700 patients hospitalized with COVID-19 in the new York City area. JAMA 2020;323:2052.

42 Carr E, Bendayan R, Gallagher K, et al. Supplementing the National early warning score (NEWS2) for Anticipating early deterioration among patients with COVID-19 infection. medRxiv 20202020.

43 Remuzzi A, Remuzzi G. COVID-19 and Italy: what next? The Lancet 2020;395:1225-8.

44 Wang D, Hu B, Hu C, et al. Clinical characteristics of 138 hospitalized patients with 2019 novel coronavirus-infected pneumonia in Wuhan, China. JAMA 2020;323:1061.

45 Grasselli G, Zangrillo A, Zanella A, et al. Baseline characteristics and outcomes of 1591 patients infected with SARS-CoV-2 admitted to ICUs of the Lombardy region, Italy. JAMA 2020;323:1574.

46 Bhatraju PK, Ghassemieh BJ, Nichols M, et al. Covid-19 in Critically III Patients in the Seattle Region - Case Series. N Engl J Med 2020;382:2012-22.

47 Petrilli CM, Jones SA, Yang J, et al. Factors associated with hospitalization and critical illness among 4103 patients with COVID-19 disease in New York City. medRxiv 2020.

48 Goyal P, Choi JJ, Pinheiro LC, et al. Clinical characteristics of Covid-19 in New York City. N Engl J Med 2020;382:2372-4.

49 Nie W, Zhang Y, Jee SH, et al. Obesity survival paradox in pneumonia: a meta-analysis. BMC Med 2014;12:61. 